\title{
AN OVERVIEW OF THE NFC-BASED SYSTEM FOR THE TOURIST GUIDANCE IN SMART CITY
}

\author{
Michal Hodoň ${ }^{21}$ \\ Gabriel Koman ${ }^{22}$ \\ Peter Ševč́́k ${ }^{23}$
}

https://doi.org/10.31410/itema.2018.59

\begin{abstract}
Development of modern technologies provides new options and enhancements in the way of tourists' involvements and experiences. By integration of various non-traditional technical means, deeper interactivity between the city and its visitors can be reached. Through this paper, the special guidance system for tourists based on the usage of smartphones will be introduced. The system utilizes special NFC sensory to guide tourist across all important sightseeing objects. The system is applied as a geocaching game, where all participants are motivated to reach all tasks as fast as possible, step-by-step visiting and investigating all objects on which the city tourism lies.
\end{abstract}

Keywords: NFC, Tourism, Guidance, Tour, Sightseeing

\section{INTRODUCTION}

$\mathrm{P}$ eople's lives are now significantly affected by mobile devices. These are especially mobile phones, resp. smartphones. Currently, this device is used to carry out even the most common activities. Just like people, mobile phones also experienced evolution. Older models were used exclusively for text and call communication. However, mobile phones nowadays have many other features. Thanks to this they basically replace the function of the computer. With powerful hardware, various applications can be run on a mobile phone. In addition to applications, these devices can also be used as a communication platform for connecting with the outside world. In particular, this enables communication technologies inside a device such as Wi-Fi (Wireless Network), Bluetooth or NFC (Nier Field Communication). It's exactly NFC communication thath is becoming more and more popular and is supported by almost all modern phones. As mobile phones are now compact and portable, users can take them practically anywhere. Considering that users can take these facilities with them as part of their leisure travel activities and so on, using mobile phones is an interesting issue also for tourism support. The paper presents the design and creation of an application for the Android platform using the NFC technology. The application presents a game based on the sightseeing of cultural monuments in Žilina. The essence of the game is to find all the selected cultural monuments in Žilina.

\footnotetext{
${ }^{21}$ Faculty of Management Science and Informatics, University of Žilina, Univerzitná 8215/1, 01026 Žilina, Slovakia

${ }^{22}$ Faculty of Management Science and Informatics, University of Žilina, Univerzitná 8215/1, 01026 Žilina, Slovakia

${ }^{23}$ Faculty of Management Science and Informatics, University of Žilina, Univerzitná 8215/1, 01026 Žilina, Slovakia
} 


\section{THEORETICAL BACKGROUND}

Near-field communication (NFC) represents a RFID system (Radio-frequency identification) that allows devices to communicate quickly with each other. [1] The distance between these devices is small using the $13.56 \mathrm{MHz}$ RFID band. [2] NFC technology is not a whole new thing. This technology has existed for several years. [3] The interest in using this technology has increased especially with the use of payment systems, specifically with the possibility of contactless payment transactions. Currently, this communication technology includes most mobile devices (Smartphones). This fact has further strengthened the relevance and usability of NFC technology in various processes that use mobile devices. [4], [5] The importance of NFC technology can be monitored even in the case of low-cost solutions because this technology provides a fast and easy way to get data. This process is simply done by attaching a device (e.g. Smartphone) to the NFC tag. In this process with NFC technology it is not necessary to pair the devices. [2] Given the speed at which information and communication technologies are being developed, NFC technology can be expected to become more extensively used in the future. This is especially the use of this technology in the low-end sector and in large-scale systems of the Internet of Things, Industry 4.0 and SmartCity. NFC technology can be applied in any way within all of the above-mentioned systems. NFC technology can be applied in any way within all of the above-mentioned systems. This article focuses on using NFC technology in the city to support users or tourists in the form of games.

\section{GAME SYSTEM DESIGN}

The Android system has been chosen as the operating system with which the app (game) will work. This operating system was chosen mainly because most mobile phones - smartphones works on the Android platform. According to portal Statista, the Android operating system has more than $80 \%$ of sold smartphones [6].

It was necessary to use more tools to create an app, resp. game on Android platform. Between these are included:

- Android SDK, contains a comprehensive set of development tools (e.g. Debugger, libraries, emulators, tutorials, etc.),

- Android Studio, the official development environment for Android platform,

- Comnent Tree, which consists of several components (Manifests, Java, Res, Gradle Scripts),

- Android Studio Emulator, which allows the development of applications without the use of a physical device, such as phone, tablet, or smartphone with Android system.

The role of the application is to communicate with the NFC tag. In NFC tags data can be stored in different forms. Within the proposed app, the data was stored in NDEF (NFC Data Exchange Format) format [7], [8].

The designed system is divided into two separate applications. The reason for the division of the solution was to prevent tag editing by the player (i.e., the regular user) in the game play process. The first application is administering. This app is used to set up an NFC tag. The second application is a game. This app is responsible for the game logic of the entire system. Logic resp. the course of the game is as follows:

1. The app will offer the user a list of monuments.

2. The user selects a monument from the menu.

3. The user has help hints at his disposal while searching for the monuments. 
4. In case user finds the monument, the content loading of NFC tag, which is placed very close to the monument itself, will run. At the same time, in the application are displayed the brief characteristics of the monument.

5. When a user finds all the monuments, the game ends.

The first application within the proposed system is the administration application. This app was designed so that common users do not have an access to it. The application is exclusively for administering the tags set by the administrator. The application name is "ZG Admin", i.e. "Zilina Go Admin". This app contains two features:

1. Content setting NFC tag, i.e. writing URL (Uniform Resource Locator) addresses, which will refer to HTML (Hypertext Markup Language) folders. The contents of these files will be brief information about monuments. Each monument will be assigned to a custom tag and an HTML file. This file will be stored on the Internet.

2. Reading the tag content, i.e. verifying the accuracy of URL addresses that are stored in tags. At the same time, this feature serves to verify that URL addresses are correct when placing the tag to the monuments itself.

The second application within the proposed system is the game application "Zilina Go". This application accompanies and helps the user search for monuments in Žilina. The task of the player is to help find ten major buildings, respectively places in the center of Žilina. Once the app is opened, the player (user) displays a list of previously unmarked monuments. In this list, the player does not have any data available on unmarked monuments. When selecting a monument, the player will see the help. At the same time, the timekeeper will start. If a player succeeds in finding a memorial at the appointed time, using the NFC tag on the monument the timekeeper stops, retrieves the information stored in the HTML file, and can continue to search for another monument. Data about monuments and games are stored in a local database. This database will be created after the installation and first open the app on the mobile device of the user.

\section{PLAYING THE GAME}

Before you can play the game itself, you need to set NFC tags first. This setting runs through the admin application. With this app, for the NFC tag it is necessary to set (see figure 1):

- URL address, which refers to a specific monument.

- Verify the write by NFC backfill.

Figure 1: Setting the NFC Tag
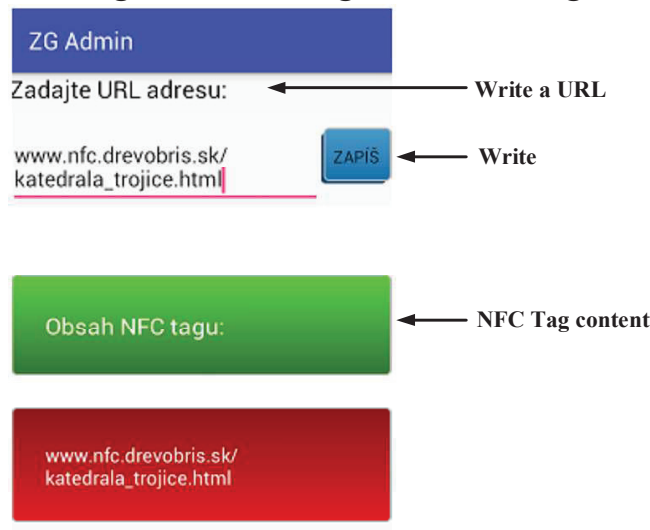
Once you've successfully set up your tags, you can play the game. When the game is turned on, the user has no monument on the screen. That means he has not found any yet. Through the navigation menu, the player gets to the list of all the sights. The player selects one of the sights and returns to the game menu where the player has the help. If a player does not know how to find a monument with the help, he can ask for more help. Showing help in the app during the game is shown in Figure 2.

Figure 2: Wanted monument

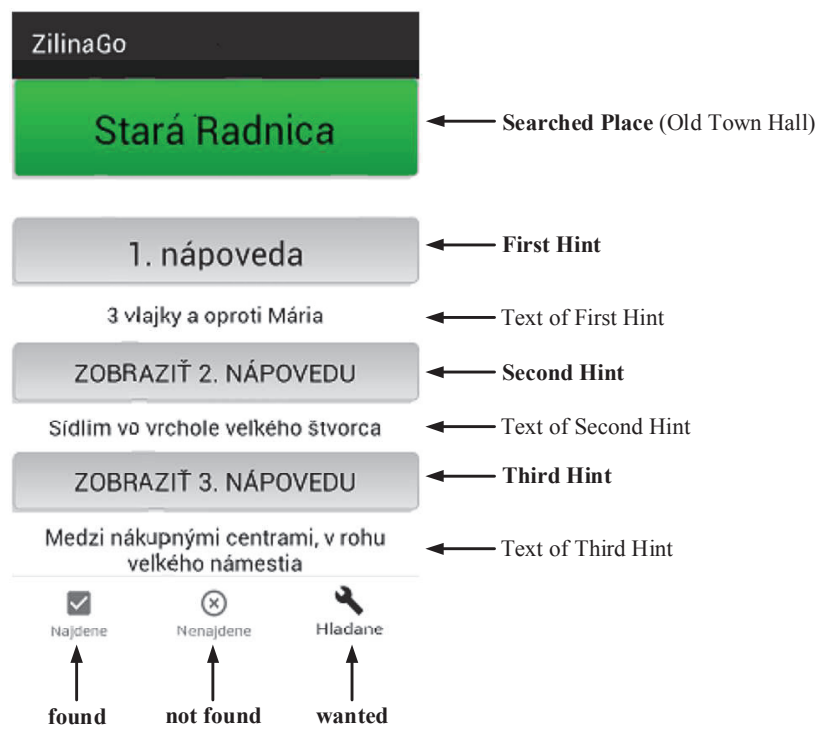

The next step in playing the game is to find the monument chosen by the player, respectively loading the correct NFC tag. If a player finds the right monument, then a new window opens when the phone is attached to the NFC tag, which includes congratulations, the resulting time of finding the monument, and some interesting insights about monuments. The appearance of found monument is shown in the following picture.

Figure 3: Finding the right NFC tag or monument

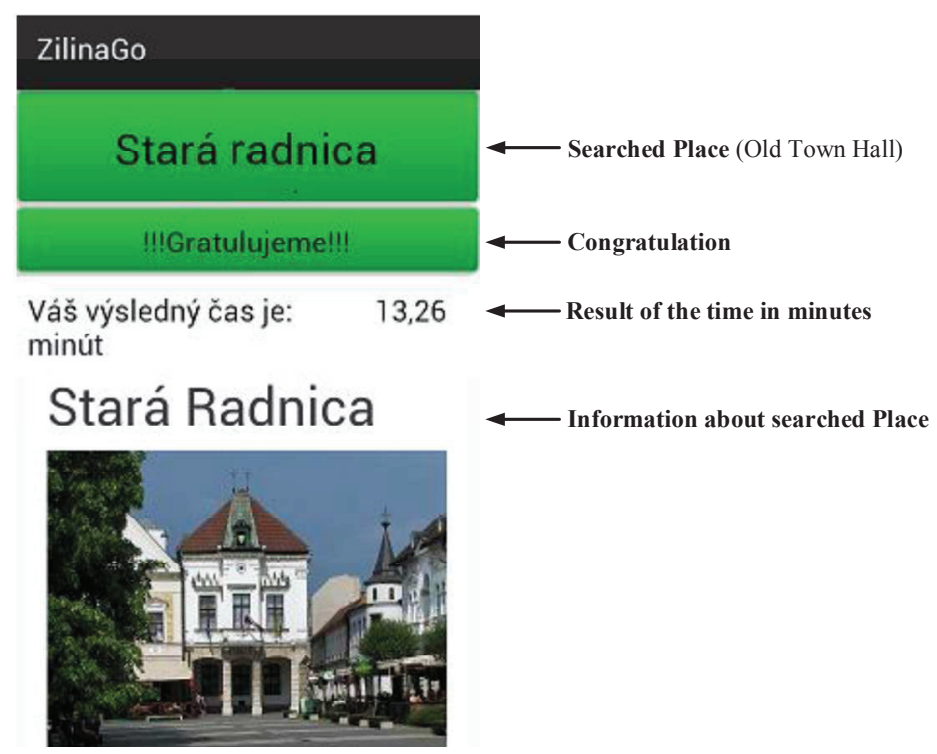


Since the monument has been successfully found, this fact will appear in the app. Once the app has been opened, the found monuments are displayed on the Home screen or in the list of found monuments (see Figure 4).

Figure 4: Records after finding the right monument

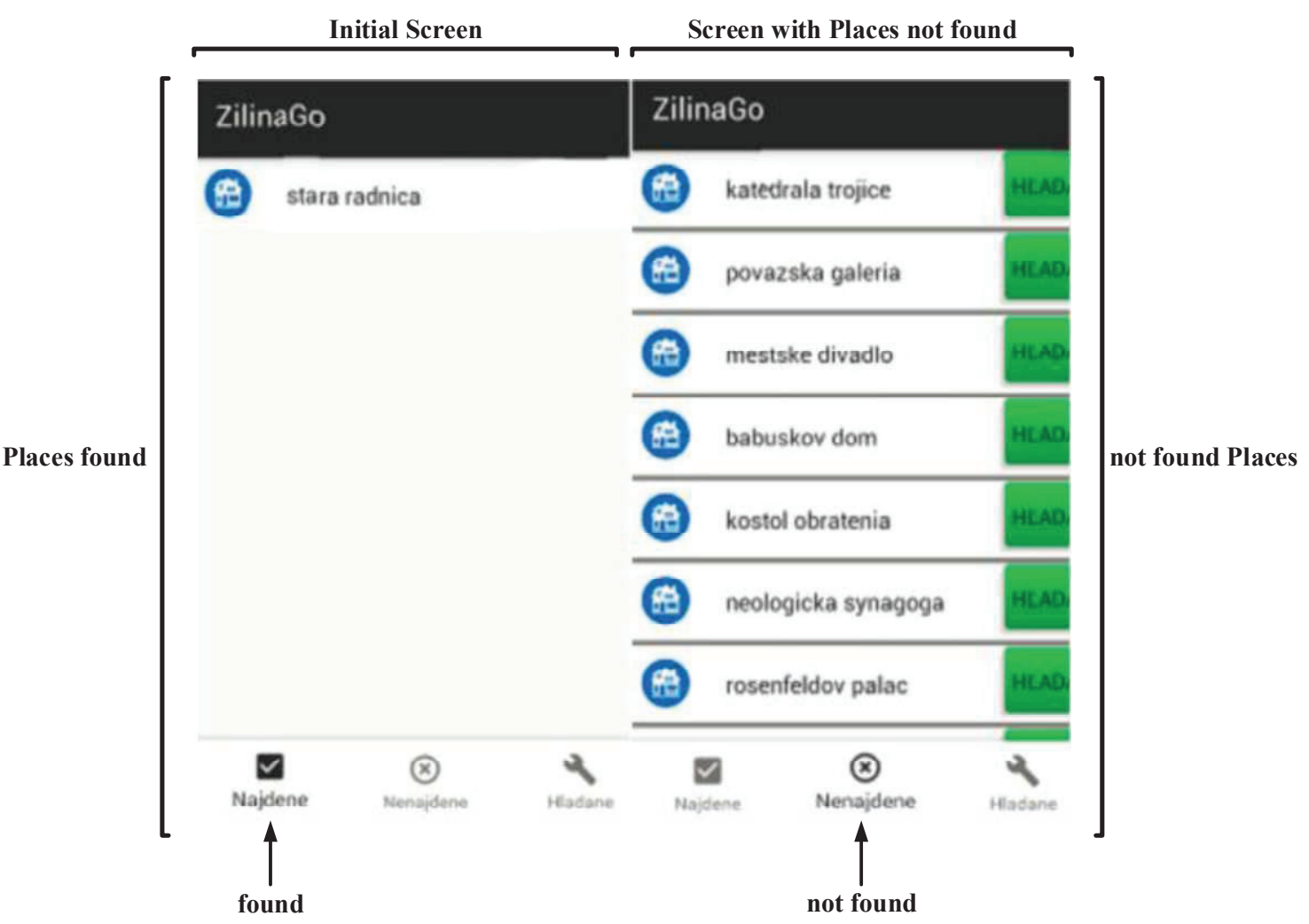

You need to repeat the gaming process to find other monuments. The game ends with finding all the sights.

\section{CONCLUSION}

The development of information and communication technologies is currently moving very fast. And thanks to technologies, people, their users, are able to travel safer, more efficient and in more comfortable way today. The proposed application or game is an instrument or option to use modern technology to support travelling and tourism. At the same time, it is possible to achieve a better orientation of people, tourists, and customers in exciting metropolises around the world. With the proposed application, it is also possible to support the building of a smart city (SmartCity). If a city is already smart, this app and the whole solution is suited for expanding the intelligent city's technology capabilities. The proposed application or the game is a more functional system between the city and tourists. While the application is complete, there is still room for improvement, such as adding new sights, improving the graphic user interface, adding statistics, comparing results with other users, organizing events via an app, and so on. All of these examples could be incorporated into the proposed system in the future to improve it. 


\section{REFERENCES}

[1] Finkenzeller, K., Müller, D. (2010) RFID Handbook: Fundamentals and Applications in Contactless Smart Cards, Radio Frequency Identification and Near-Field Communication, Wiley, New York, USA, 478 p.

[2] Lazaro, A., Villarino, R., Girbau, D. (2018) A survey of NFC sensors based on energy harvesting for IoT applications, Sensors, Switzerland, 18(11) doi:10.3390/s18113746

[3] NFC Forum. Available online: http://nfc-forum.org (accessed on 20 November 2018).

[4] Coskun, V., Ozdenizci, B., Ok, K. (2013) A survey on near field communication (NFC) technology, Wirel. Pers. Commun., 71, pp. 2259-2294.

[5] Ozdenizci, B., Coskun, V., Ok, K. (2015) NFC internal: An indoor navigation system, Sensors, 15, pp. 7571-7595.

[6] Global smartphone sales to end users from 1st quarter 2009 to 2nd quarter 2018, by operating system (in million units). Available online: https://www.statista.com/statistics/2 66219/global-smartphone-sales-since-1st-quarter-2009-by-operating-system/ (accessed on 20 November 2018).

[7] Near field communication overview. Available online: https://developer.android.com/ guide/topics/connectivity/nfc/ (accessed on 21 November 2018).

[8] Carvalho Ota, F. K., Roland, M., Hölzl, M., Mayrhofer, R., Manacero, A. (2017) Protecting touch: Authenticated app-to-server channels for mobile devices using NFC tags, Information, Switzerland, 8(3) doi:10.3390/info8030081 